\title{
First report of concentrations and implications of DDT residues in chicken eggs from a malaria-controlled area
}

\author{
Hindrik Bouwman ${ }^{\mathrm{a},}{ }^{,}$, Riana Bornman $^{\mathrm{b}}{ }$, Cobus van Dyk $^{\mathrm{c}}$, Irene Barnhoorn ${ }^{\mathrm{d}}$ \\ ${ }^{a}$ Research Unit: Environmental Sciences and Management, North-West University, Potchefstroom, South Africa \\ ${ }^{b}$ University of Pretoria Centre for Sustainable Malaria Control, and School of Health Systems and Public Health, University \\ of Pretoria, Pretoria, South Africa \\ ${ }^{\mathrm{c}}$ Department of Zoology, University of Johannesburg, Auckland Park, Johannesburg, South Africa \\ d Department of Zoology, School of Mathematical and Natural Sciences, University of Venda, Thohoyandou, South Africa \\ *Corresponding author at: \\ Henk Bouwman \\ Research Unit: Environmental Sciences and Management \\ North-West University \\ P. Bag X6001 \\ Potchefstroom 2520 \\ South Africa \\ Tel: +27 182992377 \\ Fax: +27 182992503 \\ henk.bouwman@nwu.ac.za
}

\section{Highlights}

- No published studies on DDT in chicken eggs from a malaria controlled area

- Median and maximum LDDT concentrations were 11000 and 48000 ng/g wet mass

- The maximum residue limit was exceeded 100 times

- Calculated acceptable daily intake was not exceeded (3 eggs/week/60 kg bm)

- Reductions of DDT in soil ingested by chickens may reduce human intake via eggs

\section{ABSTRACT}

In malaria endemic areas, where DDT is still used for vector control by indoor residual spraying (IRS), concentrations of DDT in human blood and breast milk are high, and there are indications of human health impact. In order to identify possible avenues of exposure reduction, we created the concept of a Total Homestead Environment Approach (THEA). THEA characterises the interactions between DDT, humans, and biota within and around homesteads. One dietary route of human exposure and uptake of DDT, namely chicken egg consumption, has, to our knowledge, never been published. ¿DDT in eggs from a DDT-sprayed village ranged between 5200-48 $000 \mathrm{ng} / \mathrm{g}$ wm (wet mass), with a median of $11000 \mathrm{ng} / \mathrm{g} \mathrm{wm}$. On a lipid mass-basis (Im), the mean EDDT for eggs from the sprayed village was $100000 \mathrm{ng} / \mathrm{g} \mathrm{Im}$. The maximum egg concentration observed was three orders of magnitude higher than the median. The acceptable daily intake (ADI) was exceeded 2.5 times based 
on a consumption of three eggs per week for a $60 \mathrm{~kg}$ person. This equates to $0.089 \mathrm{~g}$ DDT per person per year. Chicken egg consumption is therefore a possible target for exposure reduction, probably best achieved by reducing the DDT concentrations in soils.

Keywords: MRL, ADI, free-range, total homestead environment approach, THEA,

\section{Introduction}

DDT concentrations in breast milk and blood of inhabitants of dwellings treated with DDT for malaria vector control (at $2 \mathrm{~g} / \mathrm{m}^{2}$ on indoor surfaces, resulting in 64-128 g per dwelling per year (Bouwman et al., 2012)) exceed maximum residue limits up to 45 times and is a great human health concern (Aneck-Hahn et al., 2007; de Jager et al., 2009; Manaca et al., 2011; Bouwman et al., 2012). DDT has been reintroduced for malaria control in South Africa in 2000 when alternative insecticides failed (Bouwman et al., 2006). To identify targets for human exposure reduction during and after indoor residual spraying (IRS), we created the concept of a Total Homestead Environment Approach (THEA). The THEA framework characterises the interactions between DDT, humans, and biota within and around homesteads treated with DDT (Sereda et al., 2009; Van Dyk et al., 2010). One of the key components of this interaction is the uptake of DDT via locally produced food.

In many rural areas of Africa, subsistence foodstuffs are produced close to homesteads and supplemented with food from markets and shops. We found in previous studies from malariacontrolled areas where DDT is used as IRS, that food (including chicken meat and fat), soil, water, and air are contaminated by DDT (Sereda and Meinhardt, 2005; Sereda et al., 2009; Van Dyk et al., 2010). Cumulative and continuing IRS with DDT since the late 1940s has left a legacy of high concentrations indoors and in soil surrounding homesteads (Van Dyk et al., 2010). Chickens and other domesticated animals are ubiquitous around homesteads, but are not fed commercial feed. Chicken meat and eggs make up a significant proportion of the homestead-produced food diets as they are more affordable than red meat. Because DDT has also been found in high concentrations in wild bird eggs from the same area (Bouwman et al., 2013), it stands to reason that chicken eggs will also have high concentrations. We could not find any reference to DDT in chicken eggs from a malaria controlled area where DDT is currently used as IRS. Our aim is to quantify the DDT residues in chicken eggs from a malaria-controlled area, and compare the results with established maximum residue level (MRL) and acceptable daily intake (ADI) metrics.

\section{Materials and methods}

Egg collection was approved by the ethics committee of the North-West University (NWU00055-07-S3).Twelve backyard and free-roaming chicken eggs were collected during January and February 2008 (following the spaying season) from a DDT-treated village in the Vhembe District of the Limpopo province in South Africa. No significant changes to the malaria control programme have occurred since 2008 (when 63750 kg of DDT was used in South Africa Van Dyk et al., 2010), and we believe the data and findings remain relevant. Four similar eggs from an unsprayed village, $22 \mathrm{~km}$ west of the treated village, were collected as a comparison. The 'Venda' chicken breed comes from the area where we collected eggs, and lays about 153 eggs per year (Grobbelaar et al., 2010). 
Chickens are not fed commercial feed, but forage on food scraps and in the homestead areas. Eggs were chilled upon collection, and frozen on the same day. DDT was analysed by an ISO 17025 accredited laboratory (Food and Drug Assurance Laboratories, Pretoria) using the European standard method NF-EN-1528. DDT and metabolites were extracted with solid phase extraction on a C18 cartridge followed by a florisil cartridge according to Bordet et al. (2002). The analytes were eluted with petroleum ether-diethyl ether. Aldrin was used as an internal standard (it was not detected in unfortified eggs) and quantification was accomplished via fortified calibration curves. Gas chromatography - electron capture detection with a quadrupole mass spectrometer was used for quantification and identification. Quantification was via fortified calibration curves in matrix; the correlation coefficient was 0.99 . The limits of quantification ( $L O Q=3 \mathrm{X}$ noise level) were between 2.5 and $25 \mathrm{ng} / \mathrm{g}$ wm (wet mass). The lipid percentage of eggs was taken as $11.1 \%$ (gravimetric), based on unpublished data. The maximum residue limit (MRL) in eggs was $0.1 \mathrm{mg} / \mathrm{kg} \mathrm{lm}$ (lipid mass) (Codex, 1997). Acceptable daily intake (ADI) was calculated assuming a mean egg mass of $52 \mathrm{~g}$, three times per week, with a body mass of $60 \mathrm{~kg}$. The ADI standard for EDDT in eggs was taken as $0.01 \mathrm{mg} / \mathrm{kg}$ body mass (bm) per day (Codex, 2000).

\section{Results}

The results of the analyses are shown in Table 1 calculated as wet mass (wm), but also summarised as lipid mass $(\mathrm{Im})$ for the treated area. $o, p^{\prime}$-DDE and $o, p^{\prime}$-DDD were below the limits of quantification $(<L O Q)$ in all but one egg from the DDT-spayed area. Only two eggs from the reference village had quantifiable DDTs (two orders of magnitude lower than for the sprayed village) and were not used in further statistics. $p, p^{\prime}$-DDE had a somewhat higher median concentration than $p, p^{\prime}$-DDT. The percentage DDT of the $\Sigma$ DDT (sum of all DDT compounds) ranged between $23-55 \%$, with a mean of $41 \%$. On a wet-mass basis, the $\Sigma D D T$ in eggs from the sprayed village ranged between $5200-48000 \mathrm{ng} / \mathrm{g}$ wm, with a median of $11000 \mathrm{ng} / \mathrm{g} \mathrm{wm}$.

Expressed on a lipid-basis, the median $\Sigma D D T$ for eggs from the sprayed village was 100000 $\mathrm{ng} / \mathrm{g} \mathrm{Im}$; the maximum concentration was $430000 \mathrm{ng} / \mathrm{g} \mathrm{Im}$. The median concentration exceeded the MRL $(0.1 \mathrm{mg} / \mathrm{kg} \mathrm{Im}$, or $100 \mathrm{ng} / \mathrm{g} \mathrm{Im}$ ) significantly $(\mathrm{p}=0.0025$, Wilcoxon signed-rank test, Gaussian approximation). The mean daily intake of $\Sigma D D T$ via egg consumption in a sprayed village was 0.0041 $\mathrm{mg} / \mathrm{kg} /$ day bm which did not exceed the ADI of $0.01 \mathrm{mg} / \mathrm{kg} / \mathrm{day} \mathrm{bm}$.

\section{Discussion}

To our knowledge, this is the first published report of DDT in chicken eggs from an area where DDT is used as IRS for malaria control. The concentrations of DDT in chicken eggs from the sprayed village (median $=100000 \mathrm{ng} / \mathrm{g} \mathrm{Im}$ ) was three orders of magnitude higher than the reference village (190 ng/g wm, Table 1). Elsewhere in the world, DDT in chicken eggs was found in an area controlled for leishmaniasis in Brazil, exceeding the FAO maximum residue limit (MRL) by a factor of two (Vieira et al., 2001). Chicken eggs collected from markets in Jordan between 2001-07 had a mean concentration of $7.2 \mathrm{ng} / \mathrm{g}$ EDDT Im (only 22 of 134 eggs had quantifiable concentrations). Only one egg exceeded the FAO-established maximum residue level of $100 \mathrm{ng} / \mathrm{g} \mathrm{Im} \mathrm{(Ahmad} \mathrm{et} \mathrm{al.,} \mathrm{2010).}$ Eggs from different towns in Sweden collected in 1999 had a mean $\Sigma D D T$ concentration of $0.73 \mathrm{ng} / \mathrm{g}$ wm (ca. $7 \mathrm{ng} / \mathrm{g} \mathrm{Im}$ ) (Darnerud et al., 2006). Various towns in Russia had EDDT concentrations in eggs between $0.10-36 \mathrm{ng} / \mathrm{g}$ wm (ca. 1-360 ng/g Im) (Polder et al., 2010). ¿DDT was quantified in eggs from 
Table 1

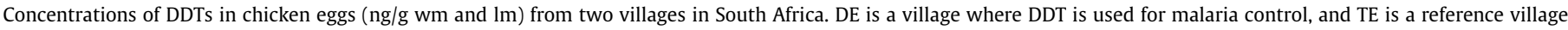
$22 \mathrm{~km}$ to the west of DE. $<$ LOQ indicates non-detection or below the limit of quantification.

\begin{tabular}{|c|c|c|c|c|c|c|c|c|}
\hline ng/g wm & $o, p^{\prime} \mathrm{DDE}$ & $o, p^{\prime}$ DDD & $o, p^{\prime}$ DDT & $p, p^{\prime} \mathrm{DDE}$ & $p, p^{\prime}$ DDD & $p, p^{\prime}$ DDT & Total DDT & \%DDT \\
\hline DE 1 & $<\mathrm{LOQ}^{\mathrm{a}}$ & $<\mathrm{LOQ}$ & $<$ LOQ & 2600 & 5.9 & 2600 & 5200 & $50^{\mathrm{b}}$ \\
\hline DE 2 & $<\mathrm{LOQ}$ & $<$ LOQ & $<$ LOQ & 2700 & $<$ LOQ & 3100 & 5800 & 53 \\
\hline DE 3 & $<\mathrm{LOQ}$ & $<\mathrm{LOQ}$ & 450 & 31,000 & $<\mathrm{LOQ}$ & 17,000 & 48,000 & 35 \\
\hline DE 4 & $<\mathrm{LOQ}$ & $<\mathrm{LOQ}$ & 160 & 6400 & 17 & 8000 & 15,000 & 55 \\
\hline DE 6 & $<\mathrm{LOQ}$ & $<\mathrm{LOQ}$ & 130 & 5000 & $<$ LOQ & 5100 & 10,000 & 50 \\
\hline DE 7 & $<\mathrm{LOQ}$ & $<\mathrm{LOQ}$ & 78 & 7600 & $<$ LOQ & 2300 & 10,000 & 23 \\
\hline DE 8 & $<\mathrm{LOQ}$ & $<$ LOQ & 89 & 7400 & $<$ LOQ & 3800 & 11,000 & 34 \\
\hline DE 9 & $<\mathrm{LOQ}$ & $<\mathrm{LOQ}$ & 78 & 8500 & 5 & 4100 & 13,000 & 32 \\
\hline DE 10 & $<\mathrm{LOQ}$ & $<\mathrm{LOQ}$ & 66 & 7800 & $<$ LOQ & 3700 & 12,000 & 32 \\
\hline DE 11 & $<\mathrm{LOQ}$ & $<\mathrm{LOQ}$ & 79 & 8200 & $<$ LOQ & 5600 & 14,000 & 40 \\
\hline DE 12 & 75 & 68 & 100 & 4900 & $<$ LOQ & 3400 & 8500 & 40 \\
\hline DE 13 & $<\mathrm{LOQ}$ & $<$ LOQ & 69 & 6200 & 5.3 & 4800 & 11,000 & 43 \\
\hline Mean & 75 & 68 & 110 & 8200 & 7.1 & 5300 & 14,000 & 41 \\
\hline Median & & & 79 & 6900 & 5.3 & 4000 & 11,000 & \\
\hline SD & & & 110 & 7500 & 5.7 & 4000 & 11,000 & 10 \\
\hline LM Mean & 680 & 610 & 1170 & 74,000 & 75 & 48,000 & 120,000 & \\
\hline LM Median & & & 760 & 62,000 & 50 & 36,000 & 100,000 & \\
\hline LM Max & 680 & 610 & 4100 & 28,000 & 150 & 150,000 & 430,000 & \\
\hline \multicolumn{9}{|l|}{$n g / g w m$} \\
\hline TE 3 & $<\mathrm{LOQ}$ & $<$ LOQ & $<$ LOQ & 110 & 5.5 & 78 & 190 & 40 \\
\hline TE 4 & $<\mathrm{LOQ}$ & $<\mathrm{LOQ}$ & $<$ LOQ & $<$ LOQ & $<$ LOQ & $<$ LOQ & $<$ LOQ & \\
\hline TE 5 & $<\mathrm{LOQ}$ & $<\mathrm{LOQ}$ & $<$ LOQ & $<$ LOQ & $<$ LOQ & $<$ LOQ & $<\mathrm{LOQ}$ & \\
\hline TE 6 & $<\mathrm{LOQ}$ & $<\mathrm{LOQ}$ & $<\mathrm{LOQ}$ & $<\mathrm{LOQ}$ & 8 & $<\mathrm{LOQ}$ & 8 & \\
\hline
\end{tabular}

a LOQ.

b Percentage of $p, p^{\prime}$-DDT of the sum of all DDTs. 
one site in Oost-Vlaanderen in Belgium; $21390 \mathrm{ng} / \mathrm{g} \mathrm{Im}$. The mean EDDT concentration of all eggs from Belgium collected in 2006-07 was 862 ng/g Im (Van Overmeire et al., 2009). IPEN (2009) analysed DDT in eggs from 18 countries. They quantified concentrations between 12.5-7041 ng/g Im. The highest concentration was from a pooled egg sample from the village of Vikuge in Tanzania, located near an old pesticide dump; soil from the dump contained $282 \mathrm{~g} / \mathrm{kg}$ DDT. Chicken eggs from Kenya contained $7000 \mathrm{ng} / \mathrm{g}$ Im LDDT (range $<100-10250 \mathrm{ng} / \mathrm{g} \mathrm{Im}$ ) (Mugambi et al., 1989). Compared with our results (Table 1), chicken eggs had concentrations at least one order of magnitude higher than the maximum listed above, and two to three orders of magnitude higher than most records. Clearly, decades of DDT application in and around homesteads resulted in elevated concentrations of DDT in chicken eggs in Limpopo. This is most likely also the case in other DDT-sprayed areas of South Africa. We sampled eggs following the spraying season - there might therefore be changes in concentrations in eggs before and after spraying seasons. Long-distance aerial transport and possibly DDT-contaminated food may be responsible for the DDT residues in the eggs from the reference village.

The concentrations of DDT in chicken eggs from the sprayed village (Table 1) corresponds to the equally high DDT concentrations in chicken meat, liver, and fat from the same area (Van Dyk et al., 2010). Chicken muscle contained a mean $\Sigma D D T$ of $700 \mathrm{ng} / \mathrm{g}$ wm, fat had a mean $\Sigma D D T$ of 240000 $\mathrm{ng} / \mathrm{g} \mathrm{wm}$, and liver had a mean $\Sigma D D T$ of $1600 \mathrm{ng} / \mathrm{g}$ wm. Chickens are omnivorous, scavenging snails, insects, termites, earthworms, grass seeds, and kitchen leftovers (Kijlstra, 2005; Klasing, 2005). In Venda, chickens are kept under extensive or semi-intensive conditions with minimal input - they mostly have to scavenge their own food (Grobbelaar et al., 2010). Chickens are also geophagous, consuming soil and small stones to assist in digestion. Kijlstra (2005) assumed ingestion of up to $20 \mathrm{~g}$ soil per day, and van der Meulen et al. (2008) found estimates in literature of $14-32 \mathrm{~g}$ soil per day. In Limpopo, outdoor soil from the same village where this study was conducted had EDDT concentrations between 5.7 and $59 \mathrm{ng} / \mathrm{g}$, with a mean of $25 \mathrm{ng} / \mathrm{g}$ (Van Dyk et al., 2010). Waegeneers et al. (2009) calculated that 23-92\% of dioxin in home-produced eggs in Belgium came from soil ingestion. Kijlstra (2005) assumed that $25 \%$ of the dioxins in ingested soils may be transferred to the chicken. Although we have not analysed any of the food items of the chickens, we can assume that a similar relationship exists in DDT-treated homesteads between soil DDT and eggs. Soils should therefore be considered as a major route of uptake of DDTs by chickens. The close proximity of the homestead soils to the DDT applied surfaces (consisting of $72 \% p, p^{\prime}$-DDT and $22 \% o, p^{\prime}$-DDT) explains the high percentage $p, p^{\prime}$-DDT (39\%, Table 1$)$ in the eggs.

Chicken eggs are an important and healthy source of nutrients (Domingo, 2014). The Codex Alimentarius adopted an MRL of $100 \mathrm{ng} / \mathrm{g} \operatorname{Im}$ EDDT in eggs (1997). The median DDT concentration we quantified (100000 ng/g Im; Table 1) exceeded this limit 100 times, or three orders of magnitude. The ADI for DDT was set by the JMPR as $10000 \mathrm{ng} / \mathrm{kg}$ bw day. The ADI in the present study (4100 ng/kg bw day) was not exceeded, based on a consumption of three eggs per week for a $60 \mathrm{~kg}$ person. The mean commercial egg consumption for South Africa is 156 eggs per person per year (2.8 per week; South African Poultry Association, 2012). It should also be pointed out that the same person in a DDT-sprayed area would also consume contaminated chicken meat and fat, adding to the contribution that poultry makes to total body burden. Based on the median EDDT concentration in eggs from the spayed village, a person eating three eggs per week would yearly consume $0.089 \mathrm{~g}$ DDT from this source alone.

Health impacts associated with DDT have been found in the Limpopo region. Mothers from IRS villages had a significantly higher risk (odds ratio $1.33, \mathrm{Cl} \% \mathrm{Cl}$ 1.04-1.72) of having a baby boy 
with a urogenital birth defect compared with women whose homes were not sprayed (Bornman et al., 2010). In addition, being a homemaker instead of being employed further increased the risk of having a baby with a urogenital birth defect (odds ratio: 1.41, 1.13-1.77). A weak association between DDT/DDE plasma concentration and the incidence of sperm with chromatin defects in men from Limpopo was found by de Jager et al. (2009). Aneck-Hahn et al. (2007) found that nonoccupational exposure to DDT was associated with impaired semen parameters in men, also from Limpopo. While it is clear therefore that urgent attention should be given to, at the very least, exposure reduction, there is also an urgent need for sustainable chemical alternatives and strategies to combat malaria (Bouwman et al., 2006; Eskenazi et al., 2009; Bouwman et al., 2012).

The THEA concept has proven useful in elucidating an important route of uptake and identified a potential target for exposure reduction. Modelling food intake scenarios should indicate whether eggs and meat are a major source of the DDT body burden of homestead inhabitants. If so, this route could be an intervention target for exposure reduction. It would be impractical to cease chicken and egg consumption altogether, but measures should be considered to limit the amount of DDT that reaches the soil, and thereby reducing the DDT concentrations in chicken eggs and meat.

\section{Funding sources}

We thank the National Research Foundation (NRF) of South Africa for funding Riana Bornman and Hindrik Bouwman. Opinions expressed and conclusions arrived at are those of the authors, and are not necessarily to be attributed to the NRF.

\section{References}

Ahmad, R., Salem, N.M., Estaitieh, H., 2010. Occurrence of organochlorine pesticide residues in eggs, chicken and meat in Jordan. Chemosphere 78, 667-671.

Aneck-Hahn, N.H., Schulenburg, G.W., Bornman, M.S., Farias, P., De Jager, C., 2007. Impaired semen quality associated with environmental DDT exposure in young men living in a malaria area in the Limpopo Province, South Africa. J. Androl. 28, 423-434.

Bordet, F., Inthavong, D., Fremy, J.-M., 2002. Interlaboratory study of a multiresidue gas chromatographic method for determination of organochlorine and pyrethroid pesticides and polychlorobiphenyls in milk, fish, eggs, and beef fat. J. AOAC Internat. 85, 1398-1409.

Bornman, R., de Jager, C., Worku, Z., Farias, P., Reif, S., 2010. DDT and urogenital malformations in newborn boys in a malarial area. BJU Int. 106, 405-411.

Bouwman, H., Kylin, H., Sereda, B., Bornman, R., 2012. High levels of DDT in breast milk: Intake, risk, lactation duration, and involvement of gender. Environ.Pollut. 170, 63-70.

Bouwman, H., Sereda, B., Meinhardt, H.M., 2006. Simultaneous presence of DDT and pyrethroid residues in human breast milk from a malaria endemic area in South Africa. Environ. Pollut. 144, 902-917.

Bouwman, H., Viljoen, I.M., Quinn, L.P., Polder, A., 2013. Halogenated pollutants in terrestrial and aquatic bird eggs: Converging patterns of pollutant profiles, and impacts and risks from high levels. Environ. Res. 126, 240-253.

Codex., 1997. http://www.codexalimentarius.net/pestres/data/pesticides/details.html?d-16497-o=2\&id=21\&d-16497$s=4 \&$ print=true

Codex., 2000. http://www.codexalimentarius.net/pestres/data/pesticides/details.html?d-16497-o=2\&id=21\&d-16497$s=4 \&$ print=true 
Darnerud, P.O., Atuma, S., Aune, M., Bjerselius, R., Glynn, A., Grawé, K.P., Becker, W., 2006. Dietary intake estimations of organohalogen contaminants (dioxins, PCB, PBDE and chlorinated pesticides, e.g. DDT) based on Swedish market basket data. Food Chem. Toxicol. 44, 1597-1606.

de Jager, C., Aneck-Hahn, N.H., Bornman, M.S., Farias, P., Leter, G., Eleuteri, P., Rescia, M., Spano, M., 2009. Sperm chromatin integrity in DDT-exposed young men living in a malaria area in the Limpopo Province, South Africa. Hum. Reprod. 24, 2429-2438.

Domingo, J.L., 2014. Health risks of human exposure to chemical contaminants through egg consumption: A review. Food Res. Int. 56, 159-165.

Eskenazi, B., Chevrier, J., Rosas, L.G., Anderson, H.A., Bornman, M.S., Bouwman, H., Chen, A.M., Cohn, B.A., de Jager, C., Henshel, D.S., Leipzig, F., Leipzig, J.S., Lorenz, E.C., Snedeker, S.M., Stapleton, D., 2009. The Pine River Statement: Human health consequences of DDT use. Environ. Health Perspect. 117, 1359-1367.

Grobbelaar, J., Sutherland, B., Molalakgotla, N., 2010. Egg production potentials of certain indigenous chicken breeds from South Africa. Anim. Genet. Resources 46, 25-32.

IPEN., 2009. DDT in eggs: A global review. International POPs Elimination Network. http://www.ipen.org/. 32 pp.

Kijlstra, A., 2005. The role of organic and free range poultry production systems on the dioxin levels in eggs. Enhancing animal health security and food safety in organic livestock production, 83 .

Klasing, K., 2005. Poultry nutrition: a comparative approach. J Appl. Poultry Res. 14, 426-436.

Manaca M.N., Grimalt, J.O., Suneyer, J., Mandomando, I., Gonzales, R., Sacarlai, J., Alonso, P.L., Menedez, C., 2011. Concentration of DDT compounds in breast milk from African women (Manhiça, Mozambique) at the early stages of domestic indoor spraying with this insecticide. Chemosphere 85, 307-314.

Mugambi, J.M., Kanja, L., Maitho, T.E., Skaare, J.U., Lökken, P., 1989. Organochlorine pesticide residues in domestic fowl (Gallus domesticus) eggs from central Kenya. J. Sci. Food Agric. 48, 165-176.

Polder, A., Savinova, T.N., Tkachev, A., Loken, K.B., Odland, J.O., Skaare, J.U., 2010. Levels and patterns of Persistent Organic Pollutants (POPS) in selected food items from Northwest Russia (1998-2002) and implications for dietary exposure. Sci. Tot. Environ. 408, 5352-5361.

Sereda, B., Bouwman, H., Kylin, H., 2009. Comparing water, bovine milk, and indoor residual spraying as possible sources of DDT and pyrethroid residues in breast milk. J. Toxicol. Environ. Health. Part A Current Issues 72, 842-851.

Sereda, B.L., Meinhardt, H.R., 2005. Contamination of the water environment in malaria endemic areas of KwaZulu-Natal, South Africa by DDT and its metabolites. Bull. Environ. Contam. Toxicol. 75, 538-545.

South African Poultry Association. 2012. SAPA industry profile. http://www.sapoultry.co.za/pdf-docs/sapa-industryprofile.pdf

van der Meulen, J., Kwakernaak, C., Kan, C.A., 2008. Sand intake by laying hens and its effect on egg production parameters. J. Anim. Physiol. Anim. Nutr. 92, 426-431.

Van Dyk, J.C., Bouwman, H., Barnhoorn, I.E.J., Bornman, M.S., 2010. DDT contamination from indoor residual spraying for malaria control. Sci. Tot. Environ. 408, 2745-2752.

Van Overmeire, I., Pussemier, L., Waegeneers, N., Hanot, V., Windal, I., Boxus, L., Covaci, A., Eppe, G., Scippo, M.L., Sioen, I., Bilau, M., Gellynck, X., De Steur, H., Tangni, E.K., Goeyens, L., 2009. Assessment of the chemical contamination in home-produced eggs in Belgium: General overview of the CONTEGG study. Sci. Tot. Environ. 407, 4403-4410.

Vieira, E.D.R., Torres, J.P.M., Malm, O., 2001. DDT environmental persistence from its use in a vector control program: A case study. Environ. Research 86, 174-182.

Waegeneers, N., De Steur, H., De Temmerman, L., Van Steenwinkel, S., Gellynck, X., Viaene, J., 2009. Transfer of soil contaminants to home-produced eggs and preventive measures to reduce contamination. Sci. Tot. Environ. 407, 4438-4446. 